\title{
京津地区主要河流的稀有分散 元素的水化学特征
}

\author{
章 申 唐以剑毛雪瑛 钱杏珍 李岫霞 \\ (中国科学院地理研究所,北京)（中国科学院高能物理研究所, 北京)
}

京津地区的主要地表水源有永定河、潮白河、北运河、萴运河和大清河等, 属海河流域的一 部分. 长期以来, 它们的水质是人们普遍关心的问题 ${ }^{[1,21}$. 本文从河流的稀有分散元素的含量 及其形态来探讨它们的水化学特性与区域的背景值.

\section{一、水样采集和分析方法}

1. 水样的采集与处理 为了获得本区水体稀有分散元素的含量水平, 在大范围的地表 水水质调查基础上,于 1980 年雨季前 (6 月)采 集了代表受人类活动影响的中、下游河段水样, 雨季后 (11 月)采集了潮河、白河、大清河上游 清洁河段的水样 (图 1). 采样时, 一份水样通 过 $0.45 \mu$ 微孔滤膜, 除去悬浮物质, 同样另一份 为原水样, 二份水样分别用纯化硝酸调至 $\mathrm{pH}=$ 2 , 供中子活化法分析.

2. 中子活化分析 取水样 100 毫升, 用 液氮冻成冰，置于冰冻干燥装置中进行低温升 华,干燥后的残渣转移至石英瓶内,与标准同时 放人反应堆中昭射 20 小时, 中子通量为 $1 \times$ $10^{13} \mathrm{n} \cdot \mathrm{cm}^{-2} \cdot \mathrm{s}^{-1}$, 样品经简单化学处理后, 用 SCORPIO $3000 r$ 谱仪测 $r$ 谱, $\mathrm{Ge}(\mathrm{Li})$ 探测器 灵敏体积为 $136 \mathrm{~cm}^{3}$, 分辨率 $1.85 \mathrm{KeV}$ (对 ${ }^{60} \mathrm{Co}$

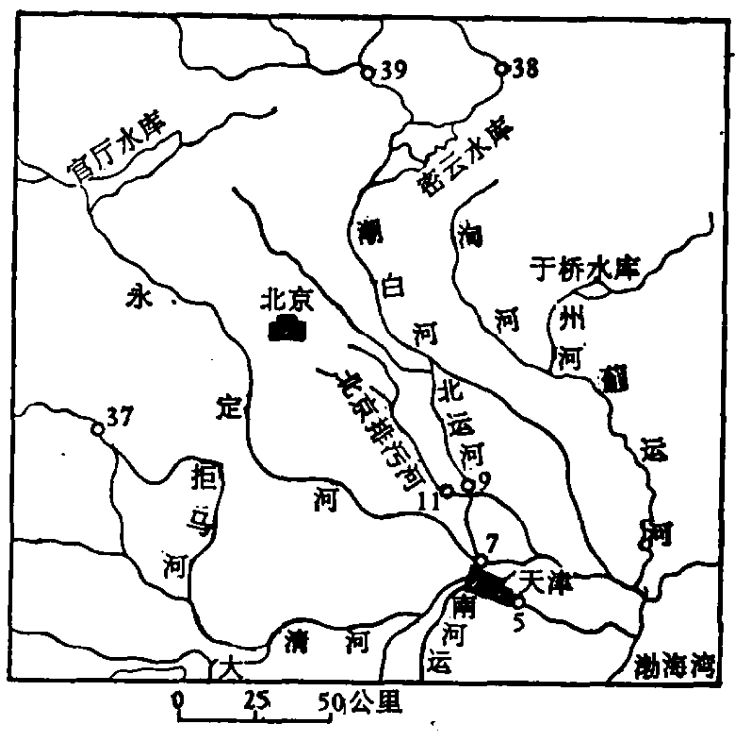

图 1 京津地区河流与采样点示意图 的 $1332 \mathrm{KeV} r$ 射线).

\section{二、结果与讨论}

分析结果列于表 1 和图 2.

1. 根据 24 个元素在河水中的含量范围和均值大致可分为如下三组: 第一组含量大于 $10 \mathrm{Ppb}$ 的有 $\mathrm{Sr}, \mathrm{Fe}, \mathrm{Ba}$; 第二组含量在 $0.1-10 \mathrm{ppb}$ 的为 $\mathrm{Mo} 、 \mathrm{U} 、 \mathrm{~W} 、 \mathrm{As} 、 \mathrm{Rb} 、 \mathrm{Cu} 、 \mathrm{Ta} 、 \mathrm{Cr} 、 \mathrm{La}$ 、 $\mathrm{Ce} 、 \mathrm{Nd} 、 \mathrm{Co} 、 \mathrm{Sb} 、 \mathrm{Ag} 、 \mathrm{Se} 、 \mathrm{Th} 、 \mathrm{Cs} 、 \mathrm{Sc}$; 第三组含量是少于 $0.1 \mathrm{ppb}$ 的有 $\mathrm{Hf} 、 \mathrm{Sm} 、 \mathrm{Eu}$.

本文 1982 年 5 月 24 日收到. 


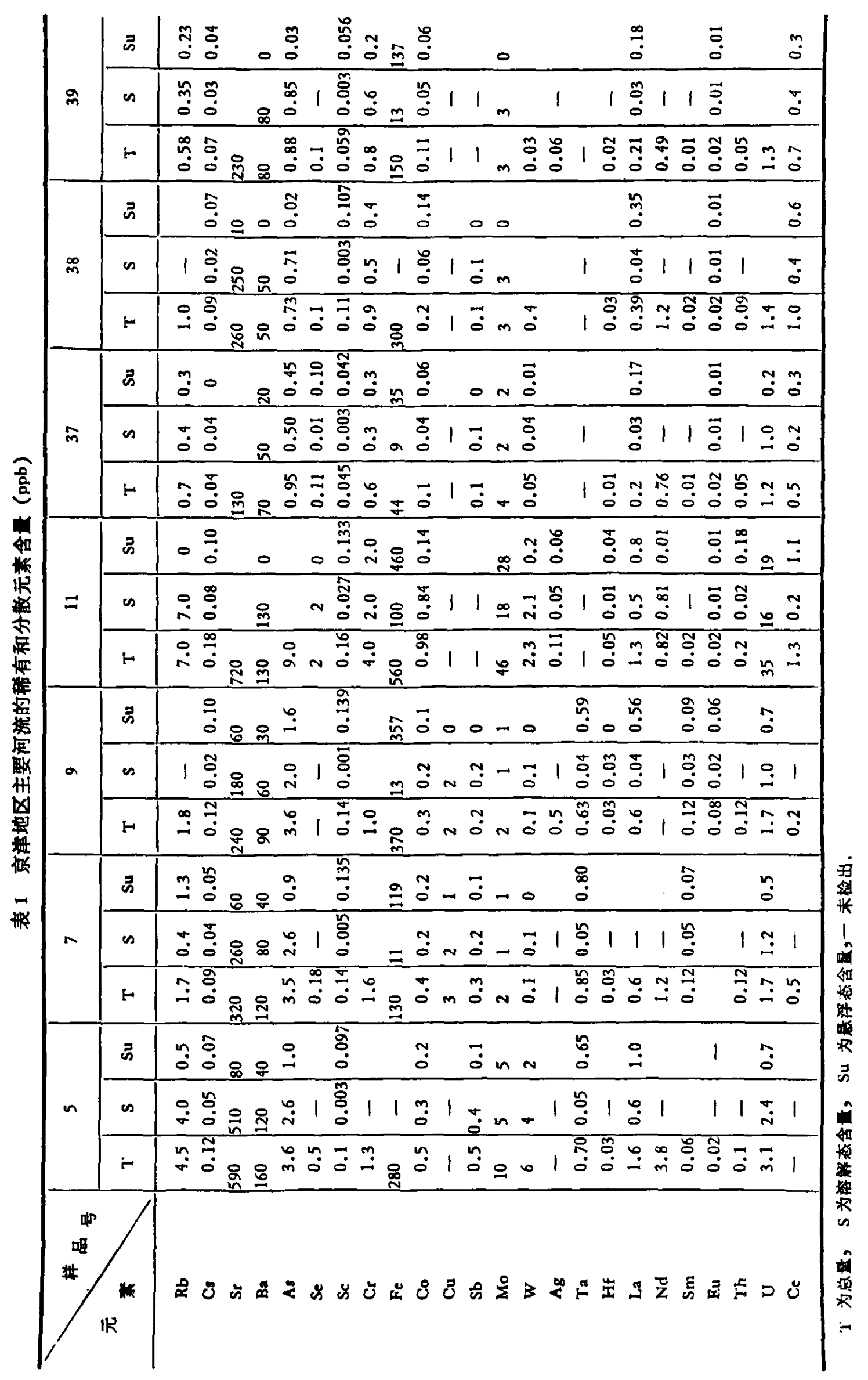


2. 从表 1 和图 2 中可见, 河水中稀有分散元素在中下游河水中的含量或多或少都大于上 游河水的背景值, 其中 $\mathrm{Rb} 、 \mathrm{Cs} 、 \mathrm{Sr} 、 \mathrm{Ba} 、 \mathrm{As} 、 \mathrm{Se} 、 \mathrm{Sc} 、 \mathrm{Cr} 、 \mathrm{Mo} 、 \mathrm{~W} 、 \mathrm{Ag} 、 \mathrm{La} 、 \mathrm{Th} 、 \mathrm{U}$ 在中、下游河 段河水中的含是明显增高, 说明河水受到本区人类活动的一定影响.

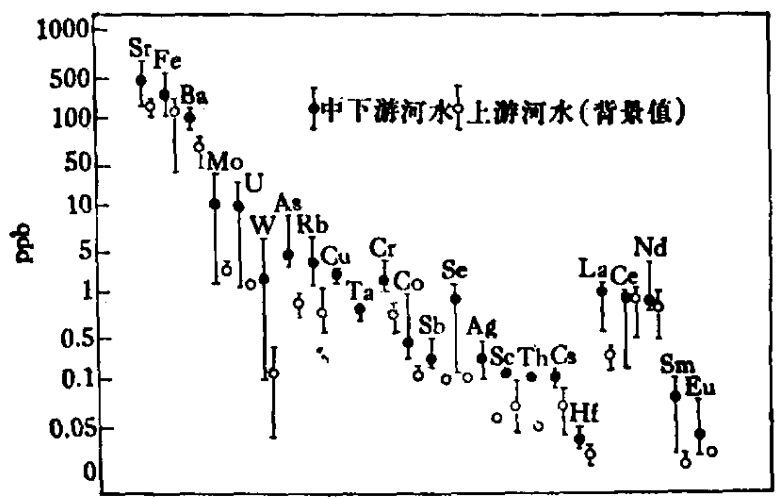

图 2 河水中稀有与分散元美总量分布

3. 由图 3 可见, $\mathrm{Sb} 、 \mathrm{Sr} 、 \mathrm{Ba} 、 \mathrm{~W} 、 \mathrm{U} 、 \mathrm{Cu} 、 \mathrm{As} 、 \mathrm{Rb}$ 在本区河水中主要呈溶解态, Co、 $\mathrm{Hf} 、 \mathrm{Cr} 、$ $\Lambda g 、 C s$ 的溶解态与惫浮态含量大致相等, 在河水中主要为悬浮态的元素是 $\mathrm{Ta} 、 \mathrm{Fe} 、 \mathrm{Sc}_{\mathrm{c}}$, 而稀 土元素悬浮态约占其总量的 $60-90 \%$.

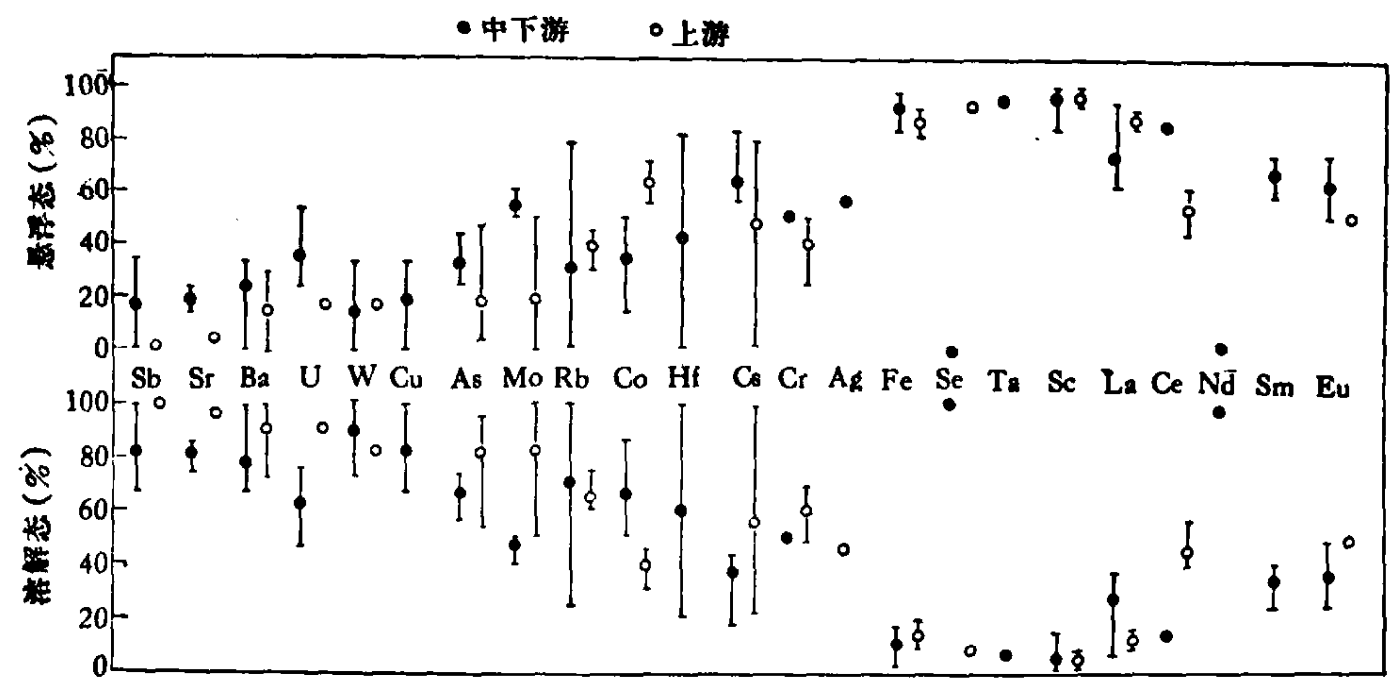

图 3 河水中稀有与分散元索形态组成百分数

4. 本区地处半干旱半湿润的气候带, 自然地理环境中的淋溶作用较弱, 河水的 $\mathrm{pH}$ 值又多 在 8 左右,因此元素的水迁移能力是比较差的, 所以上游河水中除稀土元紊外, 其他一些稀有

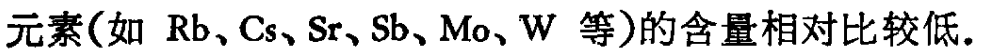

5. 河水中的稀土元素含量普遍较高, 其中尤以镰系元素 (如 La、Nd、Sm、Eu、Ce) 的含 量增加更为显著,这与流经区域的氟化物、磷酸盐矿物比较丰富有一定的关系 ${ }^{[3]}$.

\section{考文 部}

[1] Chang Shen, Environmental Protection in the People's Republic of China, State Univ. of New Jersey, 1978, 47.

[2]辛 由、唐以剑等,环境科学学报. 1(1981),4: 349 。

[3] 部水基,稀土矿物化学,中国工业出版社, 1963 . 